\title{
DE ZENDING IN HET OUDE TESTAMENT ${ }^{\prime}$.
}

De zending speelt in het Oude Testament niet de rol die men gaarne zou wensen, maar ook staat het Oude Testament niet zo afwijzend tegenover de volkerenwereld als men vaak heeft gemeend. Het $O$. T. heeft van het begin af zijn aandacht gericht op de volkeren (Gen. 12: 3), maar toch is de zending zelf eigenlijk zeer zeldzaam. Daarom kent ook de latere Joodse godsdienst de zending naar verhouding heel weinig. ${ }^{2}$ ). Als ik over zending spreek, versta ik daaronder het bewuste uit roeping uitdragen van het geloof in de wereld buiten het eigen volksleven of de eigen godsdienstige gemeenschap. Zending in deze zin heeft het oude Israël helemaal niet gekend, en het Joodse volk, voorzover het deze gekend heeft, pas heel laat en dan alleen nog maar in bepaalde kringen in het hellenistische buitenland.

Dit verwondert niet erg, omdat de israëlietische godsdienst sterk ethnisch bepaald is en volgens sommige godsdiensthistorici feitelijk nooit over het particularistische standpunt uitgekomen is; en bovendien omdat het $\mathrm{O}$. T. de zendingsgedachte heel weinig op de voorgrond heeft gebracht.

Men bemerkt, dat ik de israëlietische religie en het $O$. $T$. naast elkaar noem; ik meen, dat men werkelijk deze twee grootheden, die zo nauw met elkaar verweven zijn en zelfs niet zonder elkaar denkbaar $z$ ijn, niet geheel identificeren kan. Het $O$. $T$. is altijd nog iets anders dan een verzameling israëlietische godsdienstige geschriften, ook al kan men dit iets moeilijk nader omschrijven.

Het is inderdaad slechts op één plaats in het O.T. dat de zendingsidee in haar volheid zichtbaar wordt, of, beter gezegd, de perken van de ethnische religie doorbreekt, n.l. in de geschriften van de grote leerling van Jesaja, wiens prediking naamloos uitgegeven is en die wij aan het einde van het boek Jesaja overgeleverd vinden. Bij hem spruit de gedachte van de missie hoog op als een machtige fontein, die haar koele droppels naar alle kanten doet uitspatten. Dat is bij hem niet alleen het geval, omdat hij als balling een wijder uitzicht gekregen heeft dan b.v. zij grote meester Jesaja - inderdaad is het universalisme bij hem nog krachtiger en verhevener, dan bij de genoemde profetan en is de gedachte an Jahwe als wereldgod sterker benadrukt dan bij ieder van de andere profeten voor de ballingschap, maar dat is zo, omdat hij meer dan enig ander profeet in het komen van het koninkrijk Gods heeft geloofd, omdat hij de realiteit van het komende

1) Voordracht, gehouden 15 Mei 1953 op de gemengde Nederlands-Duitse Zendings conferentie te Oegstgeest.

2) Vergelijk Strack-Billerbeck: Kommentar zum N.T. 1924 ff.; Schürer: Geschichte des Jïdischen Volkes III 164 ff., 553 ff.; Moore Judaism. 
Koninkrijk heeft ervaren. Dit is het verborgen geheim van zijn machtige prediking. Ieder kent het begin van zijn profetie: ${ }^{1}$ ).

Hoor, iemand roept: Bereidt in de woestijn den weg des Heren, effent in de wildernis een baan voor onzen God.

Elk dal worde verhoogd en elke berg en heuvel geslecht, en het oneffene worde tot een vlakte en de rotsbodem tot een vallei.

En de heerlijkheid des Heren zal zich openbaren, en al het levende tezamen zal dit zien, want de mond des Heren heeft het gesproken.

Klim op een hogen berg, vreugdebode Sion; verhef uw stem met kracht, vreugdebode Jeruzalem; verhef ze, vrees niet; zeg tot de steden van Juda : Zie, hier is uw God!

$Z$ ie, de Here Here zal komen met kracht en zijn arm zal heerschappij oefenen; zie, zijn loon is bij $\mathrm{Hem}$ en zijn vergelding gaat voor $\mathrm{Hem}$ uit. Hij zal als een herder zijn kudde weiden, in zijn arm de lammeren vergaderen en ze in zijn schoot dragen; de zogenden zal Hij zachtkens leiden. (Jes. $40: 3,4,5,9-11$ ).

Hoe lieflijk zijn op de bergen de voeten van den vreugdebode, die vrede aankondigt, die goede boodschap brengt, die heil verkondigt, die tot Sion spreekt : Uw God is Koning.

Hoor, uw wachters verheffen de stem, zij jubelen tezamen, want met eigen ogen zien zijn, hoe de Here naar Sion wederkeert. (Jes. $52: 7$ en 8 .)

Van het begin tot het einde, Jes. $40-55$, wordt de boodschap van de profeet gedragen door wat men genoemd heeft en noemen kan de eschatologische verwachting van de profeet ${ }^{2}$ ), maar wat men misschien beter noemt, zijn onverwoestbare actualiserende geloofsrealisme.

Deuterojesaja heeft de vervulling van de belofte Gods aan zijn volk ervaren en staat weer in de tijd van de nieuwe schepping; wat God in zijn tijd doet, is voor hem scheppen. Hij gebruikt hiervoor hetzelfde woord waarmee Gen. 1 wereldscheppen aanduidt, het woord Bara. En Israël is voor hem de plaats, waar God zijn scheppende werk openbaart; daarom wordt datgene wat God met Israël doet, tot iets wat de gehele wereld in stomme verbazing brengt. Het wonder, dat God Israël doet ervaren, zullen alle volkeren zien: Jahwe openbaart zijn heilige arm voor de ogen van alle volkeren, opdat alle einden der aarde het heil van onze God zullen aanschouwen (Jes. 52: 10). God handelt met Israël, óók om daardoor de ogen van de wereld te openen voor zijn heil. De volkeren zijn getuigen van de grote verlossing, wel-

1) De Bijbel-Citaten zijn naar de vertaling van het Ned. Bijbelgenootschap.

2) Vergelijk Volz. Jes. II deselfde Der eschatologische Glaube (Festschrift Beer, 1935, S. 81). 
ke God Israël schenkt, en wel zulke getuigen, die God in $Z_{i j n}$ verlossingswerk leren zien en in een nieuwe verhouding met Jahwe komen staan.

.Vergadert $u$ en komt, nadert tezamen, gij die uit de volken ontkomen $z \mathrm{ijt}$. $\mathrm{Zij}$ hebben geen begrip, die hun houten beeld dragen en bidden tot een god die niet verlossen kan.

Verkondigt en voert gronden aan. Ja, laten zij tezamen beraadslagen. Wie heeft dit vanouds doen horen, het van overlang verkondigd? Ben Ik niet, de Here? En er is geen God behalve Ik. - een rechtvaardige, verlossende God is er buiten Mij niet.

Wendt $\mathrm{u}$ tot $\mathrm{Mij}$ en laat $\mathrm{u}$ verlossen, alle einden der aarde, want Ik ben God en niemand meer.

Want Ik heb gezworen bij Mij zelve, waarheid is uit mijn mond uitgegaan, een woord dat niet zal worden herroepen: dat voor $\mathrm{Mij}$ elke knie zich zal buigen, dat bij $\mathrm{Mij}$ elke tong zal zweren". (Jes. 45 : 20 - 23).

Jahwe is de God der wereld, en als zodanig is Hij voor de volkeren, evenals voor Israël, de Verlosser-God. Hij sticht $Z_{i j n ~} R_{i j k}$ in $Z$ ion en wil daarmee aan de ganse wereld $Z_{i j n}$ rechten schenken, omdat de wereld cp $Z_{\mathrm{ijn}}$ tora en $\mathrm{Z}_{\mathrm{ijn}}$ misjpat wacht.

„Luister naar Mij, mijn volk, en mijn natie, neig uw oor tot mii. Want een wet zal van Mij uitgaan en mijn recht zal lk stellen tot een licht der volken. Mijn zege is nabij, mijn heil treedt te voorschijn, en mijn armen zullen de volken richten; op Mij zullen de kustlanden wachten, op mijn arm zullen zij hopen." (Jes. 45: 4-5).

In deze verzen is het Jahwe zelf, die aan de volkeren het heil brengt. Bijna met dezelfde woorden als elders aan Israël de heil verkondiging word opgedragen, wordt hier gezegd, dat Jahwe de wereld zal schenken, waarop ze wacht.

Het geloof aan het spoedig intreden van het Rijk Gods in Israël en de verbreiding ervan over de gehele wereld is de bron van zendingsidee. De onmiddellijke actualisering van het Godsrijk, tezamen met volstrekte universalisering ervan, is de direkte oorzaak van het besef van de roeping tot missie. Het is dus op grond van de zich realiserende eschatologie, dat de oproep tot zending drijven aan Israël gericht kon worden, en alleen van dit geloof uit kan Israël opgeroepen worden om de zending te voeren onder de volkeren der wereld. Van hieruit heeft men de bekende pericopen. Jes. 42: 1 - 4,5 - 7 en 49: 1 - 6 te lezen.

Zie, mijn knecht, dien Ik ondersteun; mijn uitverkorene, in wien Ik een welbehagen heb. Ik heb mijn Geest op hem gelegd; hij zal den volken het recht openbaren.

Hij zal niet schreeuwen noch zijn stem verheffen, noch die op de straat doen horen. 
Het geknakte riet zal hij niet verbreken en de kwijnende vlaspit zal hij niet uitdoven; naar waarheid zal hij het recht openbaren.

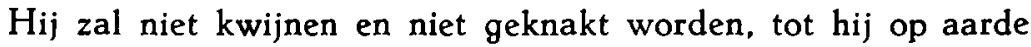
het recht zal hebben gebracht; en op zijn wetsonderricht zullen de kustlanden wachten. (Jes. 42: 1 - 4)

Zo zegt God, de Here, die den hemel schiep en hem uitspande; die de aarde uitbreidde met alles wat daaruit ontsproot; die aan de mensen, die daarop wonen, den adem gaf en den geest aan hen die daarop wandelen: Ik de Here, heb u geroepen in gerechtigheid, uw hand gevuld, $u$ behoed en $u$ gesteld tot een verbond van het volk, tot een licht der natiën: om blinde ogen te openen, om gevangenen uit den kerker te leiden, uit de gevangenissen wie in duisternis gezeten zijn. (Jes. 42:5 - 7).

Hoort naar Mij, gij kustlanden, en luistert, gij natiën in de verte. De Here heeft mij geroepen van moeders lijf aan, van den schoot mijner moeder aan heeft $\mathrm{Hij}_{\mathrm{ij}}$ mijn naam vermeld.

En $\mathrm{H}_{i j}$ maakte mijn mond als een scherp zwaard; in de schaduw zijner hand verborg $\mathrm{Hij}$ mij. Hij maakte mij tot een puntigen

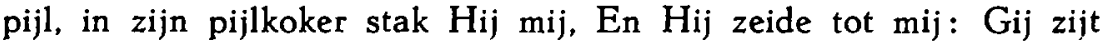
mijn knecht. Israël, in wien Ik Mij zal verheerlijken.

Doch Ik zeide: Tevergeefs heb ik mij afgemat, voor niets en vruchteloos mijn kracht verbruikt. Evenwel, mijn recht is bij den Here en mijn vergelding is bij mijn God.

Maar nu zegt de Here, die mij van den moederschoot aan vormde tot zijn knecht, om Jakob tot Hem terug te brengen en om Israël tot $\mathrm{Hem}$ vergaderd te doen worden - en ik werd geëerd in de ogen des Heren en mijn God was mijn sterkte - Hij zegt dan: Het is te gering, dat gij $\mathrm{Mij}$ tot een knecht zoudt zijn om de stammen van Jakob weder op te richten en de bewaarden van Israël terug te brengen; Ik stel uw tot een licht der volken opdat mijn heil reike tot het einde der aarde.

Ik ga bij deze pericopen van de gedachte uit, dat de knecht in hoofdstuk 49 niet mag worden gescheiden van de knecht in hoofdstuk 41 en andere, waar hij duidelijk op Israël toepasselijk is. De knecht Israël, die zijn verlossing ervaart (49:5), moet niet dit grote gebeuren als het hoogste op de voorgrond stellen, maar beseffen, dat er nog een groter ding is, nl. zijn taak om de ôr gôjjîm, het licht der volkeren, te zijn, opdat Gods heil komt tot aan het einde der wereld (49:6).

De hoogste taak bestaat hierin (42: 1 - 4), dat de knecht tot de volkeren de misjpat brengt (Volz: Die Wahrheit; Buber in Glaube der Propheten 315: Rechtsordnung), die drie maal genoemd wordt; deze misjpat hangt zamen met dat, wat daarna genoemd wordt, de tora, waarvan de vertaling ..Weisung" altijd nog de meest geslaagde 
moet worden geacht. Deze is het in het bijzonder, waarvan gezeyd wordt, dat de volkeren er op wachten. Israël heeft iets wat de volkeren onbekend is; de aanwijzing Gods, de leer van de Heilige zelf, die alles omvat wat de mensen het leven mogelijk maakt, de religieuze ken-nis, maar tevens de zedelijke en sociale en juridische Tora hangt met misjpat ook weer samen, de tora wordt in de vorm van misjpatim gegeven, die de verhouding van God en mens wederkering en de verhouding van de mensen onderling uitdrukken. Misjpat is niet alleen: recht, in de zin van positieve wetten, die bepaalde verhoudingen regelen, maar ook het Recht als de helpende, leven bevorderende macht, zoals wel blijkt uit de samenhang van vers 1,2 en 3 . Het is echter niet alleen in deze zin van hulp bieden, van het verlossen van het lijden, dat Israël de misjpat in de wereld heeft te brengen. maar het heeft nog een veel meer omvattend doel (daarom staat aan het begin van de 2 de oproep, vers 5 , de heenwijzing naar de heiligheid van Jahwe, die Israël geroepen heeft), het moet zijn berith cam en ôr gôjjìm, verbond van het volk en licht der heidenen. Het woord volk en ,.verbond van het volk" moet, evenals in het 5 de vers, waar het de betekenis van de mensheid, in de wijdste zin gebruikt; het duidt de mensen als een gemeenschap, als am aan. Israël zal een bond zijn voor de wereld, zoals Jes. 19: 24 v. Israël kent als berākhã bekereb hããrets, een zegen midden op aarde, als het volk, dat woont als middelaar tussen Egypte en Assyrië; ook kan men hier wijzen op Jes. 2 en Jes. 11, waar de Sionsberg de plaats is waar de volkeren het recht zullen leren kennen, waardoor in de wereld de vrede wordt geschapen.

Daarbij zal Israël tot licht der volkeren worden, omdat het dezen bevrijden zal uit hun noden: „Aberglaube, Demonenangst. Gewissennot" (Volz, Jes. II 156). De zending, die Israël in de wereld volbrengt, schenkt daaraan uiterlijke en innerlijke zekerheid, want Israël biedt de wereld de tora en daarmee het geloof en het rechte leven.

Israël heeft als drager van de goddelijke missie niet slechts een verlichtende, maar eerder een verlossende taak: licht en levsn en heil zijn immers in de Bijbel altijd met elkaar verbonden. Deuterojesaja weet van deze heerlijke opdracht, omdat hij God als God des levens, als Verlosser en Heiland kent. Hij kent Hem ook als degene, die weer opnieuw begint om in deze wereld zijn heerlijkheid te tonen in de verlossing van Israël en aldus $Z_{i j n}$ Rijk openbaart. Alles, wat God met Israël doet, doet $\mathrm{Hij}_{\mathrm{ij}}$ om $\mathrm{Z}_{\mathrm{ijn}}$ heiligheid aan $\mathrm{Z}_{\mathrm{ijn}}$ volk en aan de wereld te tonen, opdat de laatste met Deuterojesaja en met Israel getuige zal worden van de majesteit des Heren. Dit uitzicht op de realisering van het Godsrijk word aldus het gebcorteuur van de zendingsidee in Israël. 
Natuurlijk is dit geloof, dat zo sterk gespannen uitziet naar de komst van het Rijk Gods en dat dit zo universeel ziet, niet ontstaan in het luchtledige, maar langs meer dan één weg voorbereid. Ook reeds vóór Deuterojesaja was Israël's geloof reeds door de grootsten van zijn profeten op de volkeren gericht. Men denke slechts aan Jesaja, die in verschillende profetië als zijn verwachting heeft uitgesproken. dat de aarde vol zal zijn van de kennis des Heren, zoals de wateren de bodem der zee bedekken (11:9), en die weet, dat de volkeren zullen komen en zeggen: „Komt, laat ons opgaan tot den berg des Heren, tot het huis van den God Jakobs, opdat Hij ons zijn wegen lere" $(2: 3)$.

Op een heel andere wijze kan men de zendingsgedachte voorbereid vinden in Gen. 12:3, dat in het geschiedverhaal getuig van het geloof aan de universele betekenis van de roeping van Israël. De blik wordt reeds dan op de volkerenwereld gericht, ook al wordt de gelovige hier nog niet uit zijn eigen gemeenschap geroepen en naar de anderen buiten zijn gemeenschap heengezonden. Maar wanneer de Jahwist reeds weet van de universele betekenis van Israël, toont hij daarmee aan, dit al lang voor de klassieke profetie de volkerenwereld potentieel als wereld, die Jahwe toebehoort, was ontdekt. De volkerenwereld is dus aan Israël niet onverschillig; Israël heeft haar nooit als een barbaarse veracht, zoals de oude cultuurvolken eigenlijk altijd met hun naburige volken hebben gedaan; wij weten hoe Israël zich steeds bewust is geweest, dat het nauw verwant was aan andere volken (Gen. 10 en 11). en dat bijv. Amos het zelfs heeft gewaagd de meest gehate buurvolken, de Filistijnen en de Arameeërs als door God geleid voor te stellen (9:5). Ja, in het algemeen gesproken, heeft Israël een sterke neiging gehad naar een vreedzame samenleving met de volkeren rondom, en wij weten, hoe het zelfs in vele opzichten de assimilatie met de cultuur van allerlei omwonende volken heeft gezocht.

Naast deze trek in Israëls volks - en geestelijk leven is er een tweede geweest, die van distantiëring, van het vasthouden aan het eigen karakter en het nadruk leggen op het verschil met andere volken; deze tweede trek in Israël's geestelijk leven komt voort uit zijn geloof, uit zijn weten van het verbond Gods, uit zijn roeping Gods volk te zijn. Slechts door het evenwicht tussen deze beide kanten van het leven, door de juiste verhouding van diastase en aaneensluiting aan anderen kon Israël leven. '). In de praktijk van het leven was echter altijd op de een of andere wijze, hetzij politiek of rel:gieus, het evenwicht verbroken, en ontstonden de meest verschilende spanningen tussen Israël en de volken. Deze spanningen hebben steeds een

1) Zie: F. M. Th. de Liagre Böhl, Missions-und Erwählungsgędanken In Alt-Israël, Bertholet-Festschrift, 1950. 
normale groei van de geestelijk-religieuze verhoudingen van Israël en de volken belemmerd; en het verbaast ons niets, dat zich in plaats van een verdieping van het gevoel van verantwoordelijkheid tegenover de volkeren (ten gevolge van de geestelijke en historische ontwikkeling) steeds meer een scheiding tussen Israël en de volkerenwereld heeft ontwikkeld, en wel naar de mate, waarop de politieke, culturele en cultische verhouding was verstoord. In de kringen der gelovigen, waar de verbondsgedachte of volk-gods-gedachte sterk leefde, moest men de diastase naar voren brengen, terwijl de gedachte van de gemeenschap met de volkeren bij hen slechts kon bestaan in de vorm van de verwachting, van het visioen, van het eschatologisch uitzicht. Toch hebben deze visionnaire uitzichten hun grote betekenis gehad voor het ontstaan van de zendingsgedachte, ze hebben in de tijd van de door de historie vereiste diatase in Israël de idee van de ideële eenheid met de volkeren, het begrip voor de gemeenschap van Israël met de overige wereld bewaard; evenals in het Christendom het geloofsartikel van de ène, algemene Christelijke Kerk de zekerheid van de eenheid der Kerk altijd tot een levend geloofselement heeft gemaakt, ook bij de ergste scheuringen, en daarom gelden mag als de belangrijkste, krachtigste voorbereiding voor de oeucumenische beweging.

En zo ook is de zendingsgedachte, die door Deuterojesaja wordt uitgesproken, niet verstaanbaar zonder de visioenen van Jesaja en zonder de heilsprofetie van de Jahwistische prediking. Dit waren de historische grondslagen van de Deuterojesajaanse zendingsidee.

Achter deze historische liggen de principiële. Deze kan men vinden in de geloofsuitspraken, die met de woorden verbond en dienst worden aangeduid, of deze beide in één woord saamgevat, met het woord verkiezing. De zendingsprediking van Deuterojesaja wordt door het verkiezingsgeloof beheerst. Israël wordt knecht en uitverkorene genoemd (41: 8 en $42: 1$ ). Het is de knecht, die Jahwe ondersteunt, de uitverkorene, in wien hij een welgevallen heeft; in deze beide woorden hoort men de verbondsverhouding, die tegelijkertijd een dienstverhouding is, welke Jahwe en Israël met elkaar verbindt. God heeft Israël in zijn verbond opgenomen, zijn belofte en kracht getoond om aldus Israël tot $Z_{i j n}$ dienst te gebruiken om door Israël $Z_{i j n}$ heilig Koninkrijk in de wereld tot openbaring te brengen.

Deze verbondsverhouding is in Israël meermalen verkeerd opgevat, omdat ze geheel particularistisch slechts op Israël betrokken werd alsof God en Israël een eenheid zouden vormen tegenover de gehele verdere wereld. Inplaats dat men begreep, dat God in $\mathrm{Z}_{\mathrm{ijn}}$ verbond met Israël de bedoeling had om tot de volkerenwereld te komen. De verbondsgedachte leidde vaak tot een naturalistisch-nationalistische verhouding 
met God. Wanneer dit zo is, treden de profeten op, die zich scherp daartegen verzetten; de eerste van hen is Amos, die tegenover deze misverstanden wijst op die zware verplichtingen, die de verbondsverhouding met zich brengt $(3: 2)$, en die anderzijds op de voorgrond stelt, dat God niet alleen Israël heeft geleid, maar de andere volken der wereld; en tenslotte geeft de deuteronomistische theologie in haar formulering van de Verkiezing de juiste uitdrukking voor de verhouding van God en Israël; in deze uitdrukking, men zou ook kunnen zeggen in dit dogma (want deze formule is steeds meer het voornaamste israëlietische dogma geworden), is de wil van God de beheersende gedachte en vormen voorts de genade en de dienst de andere, even sterke, componenten : Israël staat als uitverkorene, omdat God het wil, in de dienst van de Heer voor het aangezicht der wereld. ${ }^{1}$ ).

Israël is Gods knecht, zoals Deuterojesaja sterk heeft beklemtoond; men moet echter het woord knecht hier niet te veel in de slaafse $z$ in opvatten, die het in het latere Jodendom heeft verkregen; terecht heeft Volz in zijn Jesaja-Kommentar (S. 18) betoogd, dat de 'ebed "der bevorzugte Günsteling ist der das Ohr des Herrn hat, den der Herr zu einem besondern Auftrag verwendet". De ebedgedachte staat niet zonder die van de verkiezing, zoals omgekeerd het woord van de verkiezing nooit staat zonder de gedachte van roeping of van dienst. De bijzondere taak van Israël in de wereldgeschiedenis is deze dienst van God: "Gij zijt mijn knecht Israël, in wien Ik Mij zal verheerlijken $(49: 3)^{\prime \prime}$. Israël moet niet allerlei diensten volbrengen, maar moet, zoals het is, als volk in zijn geschiedenis en in zijn leven Gods heerlijkheid, de eer van de heilige Heer der wereld, aan de volkeren openbaren. Het geredde Israël, dat door de eerste Jesaja de rest wordt genoemd, is voor Deuterojesaja het nieuwe Israël of Israël zonder meer, dat als knecht Gods zijn eer en heerlijkheid heeft te openbaren. Het bestaan en voortbestaan van Israël heeft slechts God en de wereld ten doel. Zo komt Israël, door God op het wereldtoneel geroepen, (49:1) als getuige tegenover de volkeren te staan en verkrijgt een duidelijke kennis van zijn taak, die tegelijkertijd zijn bestaansrecht vormt. De existentie van Israël heeft enerzijds met de verheerlijking van God en anderzijds met de verlossing van de volkeren uit duisternis en gevangenis te maken ( $49: 3$ en 7$)$.

Hier heeft het verkiezingsgeloof naar beide zijden ware en zijn laatste componenten gevonden. In dit besef van zijn geestelijke roeping tegenover God ten behoeve van de volkeren der wereld heeft Israël zijn goddelijke taak, zijn eigenlijke levensdoel gevonden.

De zendingsroeping behoort evenals het visioen van de lijdende knecht des Heren tot de diepste woorden van het O.T. Beide zijn

1) Zie mijn : Die Erwählung des Volkes Israël, 1953. 
echter heel weinig door Israël verstaan en opgevangen - feitelijk zijn ze pas in het N.T. door Jezus Christus gehoord en beantwoord. Men kan echter niet zeggen, dat de zendingsroep geheel verklo ken is; ook als is het in het latere Jodendom heel weinig tot actieve zending gekomen, dan is toch drieërlei gebleven: ${ }^{1}$ ).

A. het heimwee naar een geestelijke gemeenschap met de volkerenwereld in de gemeente Gods van Sion,

$B$. het reële tegemoetkomen van enkelingen, die opgenomen wilden worden in Israël.

C. ja zelfs, een zeker verantwoordelijkheidsgevoel tegenover de volkeren, die verloren gaan.

Van het eerste zijn bepaalde woorden van Zacharia en Maleachi de getuigen. Men leze Zach. 2:10 vv., 8:20 vv., Mal. 1:11, al biedt dit laatste vers enige moeilijkheden.

Het tweede vinden wij in uitspraak als Jes. 56:6 en 7, in het boek Ruth en in een Psalm als de 87ste.

En van het derde wordt getuigenis afgelegd door het veel gesmade, maar toch zo diepe boekje Jona.

Israël heeft echter nooit de laatste schreden gedaan: de grenzen tussen zich en de volkeren doorbroken. Het heeft dit niet gekund. Ten dele, omdat de eigen nationale en religieuze verhoudingen in de eerste eeuwen van de Joodse gemeente na de ballingschap in Jeruzalem groot gevaar liepen; dan ook, omdat de wet, de tora, te zeer als heilig boek geïsoleerd werd van hat gesstelijke leven en de goddelijke We sung inderdaad een wet werd, en tenslotte doordat op deze wijze de profetie verzwakte en langzamerhand practisch verstomde. De veel belovende uitzichten, die Deuterojesaja aan de wereld had geschonken, werden vergeten; evenals ten tijde van de Rzformatie ook de zending wegens de innerlijke moeilijkheden van de reformatorische Kerken op de achtergrond raakte. Eerst moest een Ander komen om het van zichzelf te verlossen en te leren, dat alleen wie zichzelf verliezen wil en in dienst aan God tot het offer bereid is. God in de wereld verheerlijken en de wereld voor God winnen kan.

Door dit alles wordt ons aan het hart gelegd:

1. Dat de zendingsroep alleen maar werkelijk kan worden gevolgd, wanneer men met de profeten en met Jezus Christus iets weet van het nabij komen van het Koninkrijk Gods. Wanneer men gelooft in de realisering van het Rijk van God hic et nunc; en

2. wanneer men iets verstaat van de verkiezing, dat is persoonlijk en als Kerk weet van God in deze wereld een taak te

1) Zie H. H. Rowley, The Missionary Message of thee O.T., 1944. 


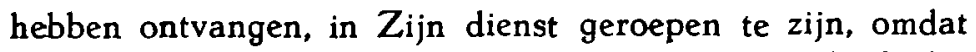
$\mathrm{Hij}$ ons het eerst heeft lief gehad. Buiten dit geloof, dat het $\mathrm{Rijk}$ Gods komt en dat wij tot $Z_{i j n}$ dienst geroepen $z i j n$, is er geen echte zending mogelijk; buiten dit geloof zal de zending altijd weer ontaarden in een hoogmoedig zichzelf doorzetten tegenover anderen op grond van een vermeende superioriteit op cultureel en geestelijk gebied en aldus op zijn best komen tot proselietenmakerij, of de zending wordt een volstrekte onmogelijkheid, een waanzinnig bedrijf.

Het is geen wonder, dat velen de zending niet vertrouwen, en dat vele anderen deze een dwaasheid noemen, want ze kan slechts daar leven en sterk zijn, waar visioenen worden geschouwd, waar het leven uit het geloof aan het Rijk Gods een realiteit is geworden en waar de liefde van God een kracht is gebleken. En dit geloof ligt niet binnen de menselijke mogelijkheden, kan een mens niet zelf grijpen, maar is een geschenk van God. Voordat Deuterojesaja spreekt over de zendingroeping van de Gebed (42:1) zegt God tot deze: ,Ik leg Mijn Geest op hem". Ook Deuterojesaja heeft geweten, dat het alleen de Geest Gods is, die de mens, ook de gelovige mens, uit zichzelf uitdrijft de vreemden tegemoet. De Geest is het, die de perken van het vrome leven doorbreekt en leert Gods heerlijkheid te zoeken in de dienst, de waarachtige geestelijke dienst aan de naaste. Deuterojesaja heeft dit verstaan, en Pinksteren heeft het ons getoond.

Groningen, Mei 1953.

TH. C. VRIEZEN. 